\title{
CONSIDERAÇÕES SOBRE O PAPEL DE CINEDEBATES NA FORMAÇÃO CULTURAL DOS CIDADÃOS
}

\author{
Adriana de Andrade ${ }^{1}$ \\ Ricardo Roberto Plaza Teixeira ${ }^{2}$
}

\begin{abstract}
RESUMO
Este trabalho investiga os resultados e impactos de atividades de extensão que organizaram sessões de cinedebates realizado no auditório do campus de Caraguatatuba do Instituto Federal de São Paulo (IFSP); desde o ano de 2015. Estes cinedebates são estruturados basicamente em torno da exibição de um filme ou documentário; seguida pela sua posterior discussão. As exibições são gratuitas e abertas para qualquer cidadão da comunidade externa do IFSP. O público, participante, é o mais variado possível: estudantes do próprio IFSP; alunos de outras instituições de ensino do litoral norte de São Paulo; professores de escolas da região; aficionados por cinema; pessoas interessadas pelos temas específicos abordados em cada cinedebates; ex-alunos do IFSP; aposentados etc. O projeto envolve debates com o público presente sobre os vídeos exibidos, na sua contextualização e na reflexão referente às questões científicas, culturais, artísticas, sociais e históricas abordadas. A metodologia utilizada buscou levar em consideração a maior diversidade possível nas produções cinematográficas escolhidas para serem exibidas, de modo a contribuir na formação de cidadãos críticos. Para que um cinedebate funcione, a contento, é necessário o rigor na escolha das obras cinematográficas e um ambiente propício; de liberdade intelectual para que aconteça um debate fraterno de ideias. É preciso também pensar nas prováveis especificidades de cada filme e nas suas consequências durante o debate. Foi possível concluir que trabalhar com filmes e documentários pode ser uma excelente ferramenta para promover reflexões e análises críticas sobre a sociedade e sobre o universo, de forma descontraída e lúdica.
\end{abstract}

Palavras-chave: Cinema. Educação. Debate. Diversidade.

\begin{abstract}
This work investigates the results and impacts of extension activities that organized cinedebates sessions held in the auditorium of Caraguatatuba campus of the Federal Institute of São Paulo (IFSP), since the year 2015. These cinedebates are structured around the exhibition of a film or a documentary, followed by their subsequent discussion. These cinedebates are free and open to any citizen of the community outside the IFSP and the participating public is as varied as possible: IFSP students themselves, students from other northern coastal education institutions of São Paulo, local school teachers, film fans, people interested by the specific topics covered in each cinedebate, IFSP alumni, retirees, etc. The project involves discussions with the public on the videos exhibited, in their contextualization and reflection on the scientific, cultural, artistic, social and historical issues addressed. The methodology used sought to take into account the greatest diversity possible in the cinematographic productions chosen to be exhibited, in order to contribute to the formation of critical citizens. For a cinedebate work well, it is necessary the rigor in the choice of the cinematographic works and a propitious and of intellectual freedom atmosphere for the fraternal debate of ideas. It is also necessary to think about the specificities of the film and about its consequences during the debate. It was possible to conclude that working with films and documentaries can be an excellent tool to promote reflections and critical analyzes about society and the universe, in a relaxed and playful way.
\end{abstract}

\footnotetext{
${ }^{1}$ Graduanda em Licenciatura em Matemática no Instituto Federal de São Paulo (IFSP) - Campus Caraguatatuba. Email: adriana-ifsp@ hotmail.com.

${ }^{2}$ Doutor em Física Nuclear pela USP. Docente do Instituto Federal de São Paulo (IFSP) - Campus Caraguatatuba. Email: rteixeira@ifsp.edu.br.
} 
Keywords: Cinema. Education. Debate. Diversity.

\section{Introdução}

O cinema é um dos entretenimentos mais intenso da sociedade em toda parte do mundo, e assistir um filme possibilita que viajemos no tempo e no espaço, experimentando a sensação de sermos os protagonistas da trama, vivenciando os mais diferentes momentos da história da humanidade. O cinema consegue por meio das emoções suscitadas, sensibilizar as pessoas de diversas origens sociais, culturais e étnicas. O cinema pode ser trabalhado como uma poderosa ferramenta educacional; deste modo, levar o cinema para o âmbito educacional é proporcionar que aqueles que estão mais acostumados apenas com o cinema comercial, comum na televisão e nos shoppings, possam experimentar e compreender outros tipos de cinematografias, compartilhando esta experiência com outras pessoas; e na sequência analisando as obras exibidas de forma estruturada e com os conhecimentos necessários para ir além da superficialidade que geralmente ocorre quando se encara uma obra cinematográfica apenas como entretenimento.

O cinema permite que o cidadão se transporte para diversas outras realidades. Por meio dessas reflexões, o estudante cria ferramentas cognitivas para analisar os avanços que ocorreram historicamente em diversas esferas - tais como os direitos humanos, ao mesmo tempo em que paralelamente reflete sobre os problemas que ainda permeiam a sociedade, no que diz respeito às questões como: desigualdade social e guerras, por exemplo. $\mathrm{O}$ cinema pode também provocar junto a esses jovens momentos de reflexão, sobre o quanto é necessário avançar em inúmeras questões que dificultam a vida de diferentes grupos sociais, entre eles: as mulheres, os negros, os homossexuais e os migrantes. De acordo com Andrade e Teixeira (2016), utilizar o cinema como ferramenta educacional, requer o desenvolvimento de capacidades cognitivas de modo que o aluno seja capaz de realizar questionamentos:

O cinema permite passear por espaços e tempos desconhecidos, convidando-nos a "sermos outros", a nos colocarmos na posição do outro - de um estrangeiro, de um índio, de um negro, de uma mulher, de um velho, de uma criança, de um homossexual, de um imigrante, etc - de modo a trabalhar os preconceitos, ensinando a ser aquilo que não somos, a ser múltiplos: o bom cinema pode colaborar para desenvolver a alteridade e a empatia (ANDRADE; TEIXEIRA, 2016). 
Trabalhar o cinema como ferramenta educacional informal, proporciona um aprendizado que permita refletir sobre as cenas observadas. Esse resultado depende, obviamente, que se assista previamente o filme para que haja uma discussão em grupo, preparando uma intervenção caso o assunto seja polêmico ou razoavelmente novo para todos. Este é o tipo de prática que os extensionistas têm desenvolvido nos cinedebates. Com a realização de sessões de exibição, seguidas de debates de obras cinematográficas, no âmbito do campus de Caraguatatuba do Instituto Federal de São Paulo (IFSP). Os extensionistas assistem previamente a obra em questão e procuram instigar o público presente a refletir sobre a amplitude e a complexidade dos temas suscitados por ela, sempre que possível, trazer a discussão para questões que atingem os presentes na atualidade.

Conforme afirma Napolitano (2009) “(...)no trabalho escolar com filmes, desde que devidamente organizado, o professor pode adensar esta experiência, para ele e para os seus alunos, exercitando o olhar crítico e encantando, ao mesmo tempo." Assim é fundamental que se façam: "reflexões e análises a respeito dos filmes exibidos, por vários pontos de vista possíveis: histórico, artístico, científico, filosófico, político, cultural, educacional, econômico, social, musical, tecnológico, etc.” (ANDRADE; TEIXEIRA, 2016).

Planejar uma atividade de cinema na escola exige, antes de mais nada, que não se subestime o público presente. Esse público, e qualquer outro, traz consigo um acúmulo de referências e informações sobre o tema abordado. É preciso também pensar sobre o tempo que os presentes dispuseram para assistir ao filme, preparando-o atenciosamente para proporcionar momentos reais de reflexão:

Refletir a respeito de um filme é destrinchá-lo de modo a compreender as suas ideias e a sua Ideologia, percebendo o que há de implícito nas entrelinhas e que não se nota assistindo uma única vez, ou seja, implica em desconstruir o filme para compreender melhor todo o conjunto de elementos peculiares do enredo. (GOLIOT-LÉTÉ, 2012 apud ANDRADE; TEIXEIRA, 2016).

Quando um filme é exibido em uma instituição de ensino fora do horário de aula, o público alvo tem que ser levado em consideração na divulgação do evento e na escolha do enredo do filme, pois, as pessoas são atraídas para uma atividade de cinedebate por diversos motivos. Segundo Napolitano (2005) o cinema está dentro da indústria de cultura e lazer, com narrativas sedutoras, 
atrizes e atores conhecidos, e nessa esfera, é fundamental que o mediador do filme esteja apto para fazer essa intermediação entre cinema - educação - público. Conforme (NAPOLINO, 2015 apud MOGADOURO, 2011):

A diferença é que a escola, tendo o professor como mediador, deve propor leituras mais ambiciosas além do puro lazer, fazendo a ponte entre emoção e razão de forma mais direcionada, incentivando o aluno a se tornar um expectador mais exigente e crítico, propondo relações de conteúdo/linguagem do filme com o conteúdo escolar. (NAPOLINO, 2015 apud MOGADOURO, 2011)

Escolher cuidadosamente um filme histórico para ser exibido numa instituição educacional, por exemplo, requer que o responsável pelo evento seja analítico, tendo rigor na escolha da trama, e antecipe alguns dos impactos que poderá ocorrer no público presente, tendo em vista os objetivos que se queira alcançar.

O professor deve ver o filme histórico como uma representação do passado produzida em épocas e por sociedades que nem sempre têm ligação imediata com o acontecimento histórico representado, ou, tampouco são herdeiras diretas daquela história encenada. Por isso, mais importante é ver o filme como um documentário da sociedade e da época que o produziu, que projeta seus valores e suas questões sobre o passado representado. (NAPOLINO, 2015 apud MOGADOURO, 2011).

Entre os procedimentos para que um cinedebate seja bem-sucedido, é pertinente que o professor pense sobre o ambiente em que o filme será exibido e a qualidade do som, da imagem e da legenda do vídeo que será trabalhado. Conforme Mogadouro (2011):

O planejamento de tempo da exibição e o bom funcionamento do suporte tecnológico interferem na qualidade da atividade, à medida que a opção de exibir o filme na íntegra ou de forma fragmentada deve ser pensada com antecedência. A falha dos equipamentos na hora " $h "$ também pode frustrar a atividade, o que está bastante relacionado à insegurança de professores no uso dos filmes. (MOGADOURO, 2011)

O mediador deve preparar o público presente, proporcionando momentos de reflexão acerca da trama que será exibida, de modo que o cidadão presente não seja apenas um mero consumidor 
da indústria cultural (ANDRADE et al., 2017). Deve-se incialmente apresentar a obra audiovisual que será exibida, sem dar spoiler, mas fornecendo algumas informações sobre a época, os personagens e outras questões pertinentes que instigarão os presentes a refletir sobre o filme de um modo mais amplo. Estes são procedimentos fundamentais para o sucesso de um evento de cinedebate. É importante também lembrar que assistir um filme numa instituição pública de ensino não é como assistir em casa ou em um cinema comercial: o organizador desta atividade está nesta empreitada a fim de criar uma cultura da valorização da tolerância, do respeito, da diversidade e da produção cultural de outros povos e de outras épocas: "Nessa relação cinema-educação, texto $e$ contextos se intercruzam e o texto fílmico será um dispositivo que opera a partir de uma rede de saberes sociais" (EUGENI, 1999, apud FANTIN, 2007).

\section{Materiais e métodos}

Este trabalho é uma reflexão acerca do programa de extensão: "Cinedebate e atividades de educação científica e cultural" que vem sendo implementado no campus de Caraguatatuba do Instituto Federal de São Paulo (IFSP) desde 2015, tendo como fonte de financiamento para as bolsas dos extensionistas e a aquisição de equipamentos da Pró-Reitoria de Extensão (PRX) do IFSP.

O ponto de partida deste trabalho foi o desenvolvimento a partir de 2012 de um projeto de iniciação científica, denominado: "Cineclube Científico Itinerante”. Este projeto organizou palestras e atividades educacionais, em diferentes escolas da região do litoral norte, para trabalhar a ciência presente em cenas recortadas de documentários e filmes, como foi o caso, incialmente dos filmes da saga: "O Planeta dos macacos". O projeto se prolongou nos anos seguintes em outros projetos de iniciação científica e de extensão que contemplavam o uso de material audiovisual para a execução de ações culturais ou educacionais, com uma maior ênfase no âmbito da divulgação científica. Em 2015, foram implantados dois projetos de extensão (“Cinedebate" e "Atividades de educação científica"), que a partir de 2016 foram fundidos em um só programa de extensão - que, neste contexto, é definido como sendo o resultado da fusão de pelo menos dois diferentes projetos de extensão.

O manuscrito focaliza as atividades de cinedebates realizadas por este programa de extensão, mas é importante lembrar que ele também envolveu a elaboração de palestras, cursos e 
atividades de divulgação científica em campos de saber como: a astronomia, a física e a matemática, que em alguns casos estiveram relacionadas com alguns dos cinedebates realizados. Por exemplo: quando se tratavam de filmes de ficção científica ou de filmes sobre a vida e o passado de grandes cientistas. No ano de 2016, este programa de extensão envolveu 10 (dez) bolsistas de extensão selecionados - dentre os estudantes do IFSP-Caraguatatuba - para implementarem as atividades propostas, sendo que em 2017 o número de bolsistas de extensão envolvidos caiu para 8 (oito), de acordo com os editais da Pró-Reitoria de Extensão do IFSP que regulamentaram o programa. Além dos bolsistas de extensão, os bolsistas de iniciação científica orientados pelo coordenador do programa (entre 3 e 4, dependendo do ano) também participaram ativamente das atividades realizadas.

Desde a sua gênese o programa procurou contemplar a metodologia CTSA (CiênciaTecnologia-Sociedade-Ambiente) e respeitar o princípio de trabalhar com uma grande diversidade nas produções cinematográficas das obras escolhidas, de modo a contribuir para a formação de cidadãos críticos: “(...) ao priorizar a compreensão da ciência e tecnologia como produtos históricos da atividade humana e com impactos ambientais, sociais e econômicos, fornece subsídios para a transformação de muitas das práticas e dos pressupostos existentes no contexto educativo" (LEITE; FERRAZ, 2011 apud ANDRADE; TEIXEIRA, 2016).

A execução de um cinedebate envolve várias etapas - gerenciadas pelo coordenador do programa de extensão - para que o evento possa de fato atingir os seus objetivos. Um dos objetivos é: elaborar uma lista prévia de filmes que tenham potencial para serem exibidos em um cinedebate; assistir diversos dos filmes sugeridos; escolher os mais adequados ao público; ler e pesquisar a respeito destes filmes em sites como <www.imdb.com> ("Internet MovieDataBase"); obter ou adquirir os filmes escolhidos para a exibição; conferir a qualidade do áudio e da imagem, bem como a qualidade da legenda e a sua sincronia; decidir a respeito da apresentação da obra legendada ou dublada; escolher dia e horário para a exibição da obra audiovisual; reservar o auditório do IFSP-Caraguatatuba (ou um outro espaço) para a realização do cinedebate; definir o perfil do público que se deseja que esteja presente; escrever um texto e elaborar um banner para divulgar o cinedebate que ocorrerá publicando-os no site do IFSP-Caraguatatuba (no espaço que foi definido em 2017 para informar a respeito dos cinedebates que ocorrerão), nas redes sociais (na página do Facebook "Cine Debate IFSP Caraguatatuba") e no site < www.cinedebate.com.br $>$ elaborado no 
âmbito deste programa de extensão para ajudar nesta divulgação; estruturar um "evento" na rede social (Facebook) para informar sobre a atividade que ocorrerá; fazer cartazes para divulgação do cinedebate para serem impressos em papel; levar e entregar estes cartazes (impressos) em escolas e instituições culturais, onde cartazes possam ser afixados para a divulgação.

Outras atividades que são, também, importantes, são: divulgar o cinedebate em sites de informações do litoral norte paulista, na imprensa em geral e em rádios e TVs; convidar palestrantes para comentarem os filmes após a exibição; preparar previamente o auditório no dia da exibição; conferir o ar condicionado e os equipamentos de projeção e de áudio; verificar a limpeza do local; conferir a imagem e o som do filme, pelo menos meia hora antes da projeção; receber o público presente; tirar fotos do evento para serem publicadas posteriormente; zelar pelo bom comportamento dos presentes durante a exibição; colaborar com a dinâmica do debate após a exibição; anotar os principais pontos debatidos para serem usados em um artigo posterior; conduzir os presentes ao final do debate; desligar os equipamentos e deixar o auditório limpo e pronto para uso posterior; escrever um texto (com as fotos tiradas) sobre o cinedebate que ocorreu para ser publicado no site do IFSP-Caraguatatuba, de modo que possa ser reproduzido pelas redes sociais,

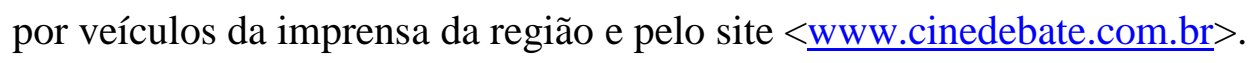

Além disso, é importante elaborar a lista de presença em arquivo no formato word (para os presentes incluírem o nome); imprimir esta lista de presença, grampeá-la, passar a lista de presença sobre uma prancheta para ser preenchida pelos presentes com seus nomes durante o cinedebate (acompanhada de prancheta e caneta) e escanear a lista para um arquivo do tipo pdf. Em alguns casos é necessário montar uma mala direta com declarações de que determinados estudantes do IFSP-Caraguatatuba participaram o cinedebate (particularmente para os estudantes dos cursos superiores que precisam de horas acadêmicas ou complementares referentes à participação em atividades culturais) e enviar estas declarações para os coordenadores destes cursos por e-mail. Para estudantes de outras universidades que precisarem de uma declaração de que estiveram presentes é necessário providenciar esta declaração impressa, preenchida e assinada em papel, ao final do cinedebate. 
Figura 1 - Cartaz de divulgação de um cinedebate que foi realizado

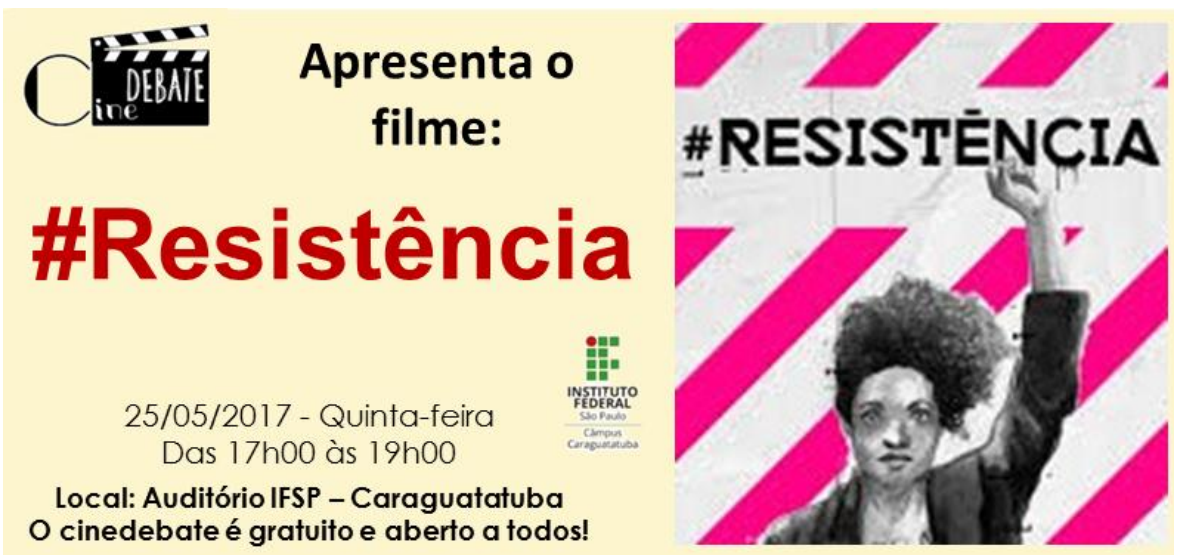

Como os recursos deste programa de extensão foram adquiridos dois telescópios para o IFSP-Caraguatatuba (um telescópio refrator e um telescópio refletor). Em alguns casos de cinedebates que terminam no período noturno, quando o céu não está nublado, são montados os telescópios no pátio externo do IFSP-Caraguatatuba, que fica nos fundos do auditório, e os presentes são convidados para observarem corpos celestes, tais como a Lua e planetas como: Júpiter e Saturno, após o final do evento. É um modo sútil de lembrar que observar e refletir sobre o universo em que vivemos é talvez o mais antigo tipo de "cinedebate" que existe.

Figura 2 - Layout do site cinedebate.com.br - criado para registrar e divulgar eventos do Projeto de Extensão Cinedebate




Os artigos sobre as sessões de cinedebate realizadas no IFSP-Caraguatatuba estão registrados no site do projeto <www.cinedebate.com.br $>$ e no site da própria instituição <www.ifspcaraguatatuba.edu.br . Eles podem ser facilmente consultados por todos aqueles que quiserem conhecer melhor as atividades que foram realizadas e os diferentes filmes e documentários que foram escolhidos para serem exibidos. Muitas das obras escolhidas estão disponíveis e podem ser gratuitamente adquiridas em sites que armazenam vídeos, tais como: o youtube e o dailymotion, dentro outros meios: blogs, torrent, plataformas como o "videocamp", etc.

\section{Resultados}

O IFSP-Caraguatatuba está situado na região do bairro do Indaiá, em localização de fácil acesso para toda a cidade, o que facilita a participação dos estudantes secundaristas de muitas escolas da cidade. Com três anos de atuação, as atividades de cinedebate conseguiram adquirir uma tradição própria, permitindo à comunidade entender que transcendia o estereótipo do cinema comercial, trazendo ao público um cinema que não é valorizado comercialmente e ampliando o repertório cultural dos presentes. Desse modo, os participantes podem refletir com profundidade sobre valores e vivências. Com base nos dados obtidos durante a implementação das atividades deste programa de extensão, percebemos que o fortalecimento das atividades de cinedebate se deve à excelente infraestrutura que o auditório do IFSP-Caraguatatuba possui. São cerca de 100 lugares, com poltronas confortáveis, em um ambiente escuro sem janelas, silencioso, com ar condicionado. Possui um excelente som e imagem boa, o que o torna muito favorável para a exibição dos filmes em qualquer horário. Já foram realizadas sessões de cinedebates no auditório do IFSPCaraguatatuba nos períodos matutino, vespertino e noturno dos cinco dias úteis das semanas (segunda-feira a sexta-feira) e nos sábados pelas manhãs. Mas a grande maioria das sessões foram realizadas nos finais das tardes e início das noites dos dias úteis. Foram realizados cinedebates em espaços de escolas parceiras deste programa, mas em alguns dos casos as condições de infraestrutura (luminosidade, silêncio etc) não foram favoráveis a exibição e discussão de uma obra cinematográfica em uma atividade que muitas vezes tem a duração de cerca de duas horas e meia.

Assim sendo, a decisão geralmente é: realizar as sessões de cinedebate no auditório do IFSP-Caraguatatuba e divulgar as atividades da melhor forma possível. De modo a atrair o maior número de interessados da comunidade externa e interna ao IFSP para participarem dos eventos. No âmbito do IFSP-Caraguatatuba, já foi realizada aproximadamente uma centena de cinedebates 
ao longo dos últimos anos, abrangendo uma grande diversidade de temas, filmes e documentários. Sobre todos os cinedebates realizados há artigos informativos sobre as discussões que ocorreram e que podem ser consultados no site: 〈www.ifspcaraguatatuba.edu.br $>$.

Figura 3 - Público no auditório do IFSP-Caraguatatuba em um cinedebate

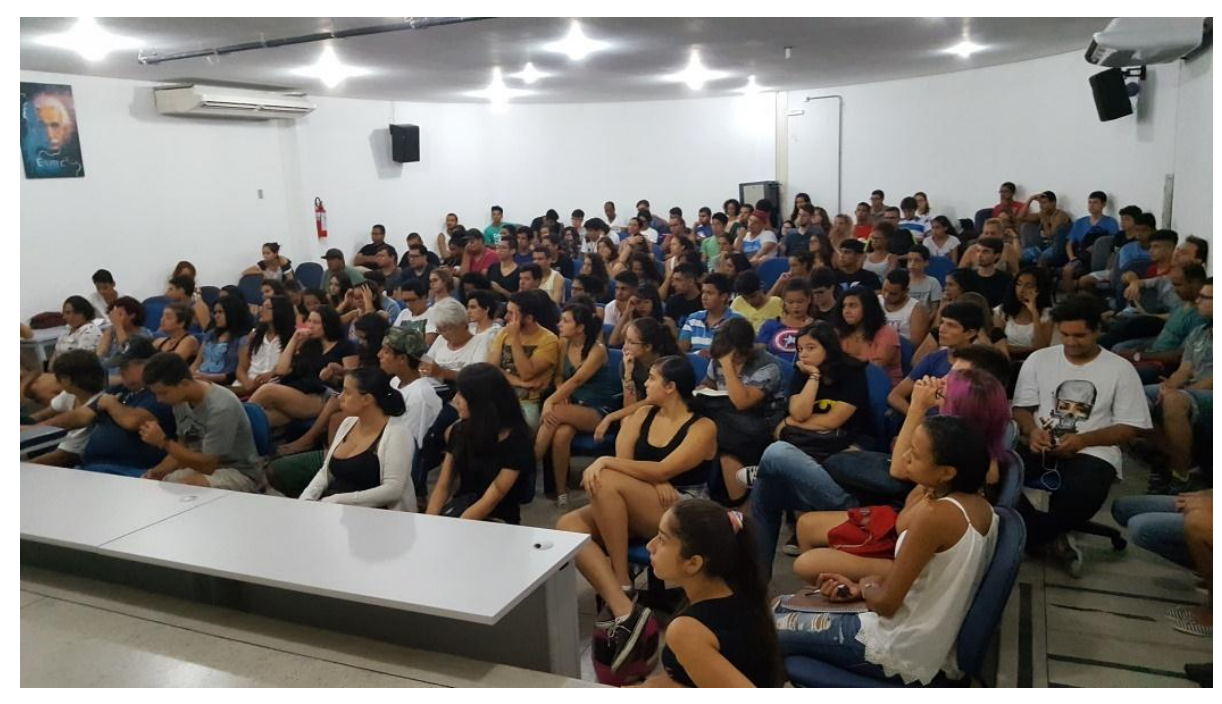

Dentre as diversas obras exibidas e discutidas em cinedebates desde 2015 estiveram os seis primeiros filmes produzidos para a saga: "Guerras nas estrelas"; os filmes "A volta para casa" e "Além da escuridão" da saga "Jornadas nas estrelas", "Elysium", "Oblivion", "Viagem à Lua de Júpiter", "Sociedade dos Poetas Mortos", "Contato", "Interestelar", "Diários de Motocicleta", "Che - Parte 1 (O argentino)", "O Código da Vinci", "Anjos e Demônios”, "Apocalypse Now”, "Nascido para matar", "Amém”, “A chave de Sarah", "Ela”, "Blade Runner - O caçador de androides", “O sonho de Wadjda", "Geração roubada", "Prometheus", "Viva a Rainha”, "Raul: o início, o fim e o meio", "Somos tão jovens", "A família Bélier", "Um grito de socorro", "Cyberbully", "Primeiro da classe", "Gravidade", "Perdido em Marte", "As sufragistas", "Histórias cruzadas”, "No”, “O dia em que eu não nasci”, "É possível viajar no tempo?” e "Estamos na matrix?" (documentários da série "Pelo buraco de Minhoca"), "Exo-Planeta Aurélia" (documentário da série "Extraterrestres"), "Criação", “A Teoria de Tudo", "Chico - Artista brasileiro", "Vinicius”, “Orações para Bobby”, “O primeiro que disse”, "Lute como uma menina”, "Batismo de sangue", "O dia em que meus pais saíram de férias", "Trashed - Para onde vai o nosso lixo", "Mandela - A luta pela liberdade", "Invictus", "Mandela - O caminho da liberdade”, “Tudo que aprendemos juntos", "Vista a minha pele", "Uma história de amor e de fúria", "\#Resistência", 
"2001 - Uma odisseia no espaço", “A onda”, “A vida de Brian”, “A vida dos outros”, “ABC da greve”, “Adeus Lenin”, “Bem-vindo”, “Capitão Fantástico”, “As vidas das estrelas” (episódio da série “Cosmos” produzida por Carl Sagan), "Algo que as moléculas são capazes de fazer” (episódio da série "Cosmos" produzida por Neil de Grasse Tyson), "Eles vivem", "Fahrenheit 11 de setembro", "Marighella", "Muito além do jardim", "Na natureza selvagem", "O barco da esperança", “O Concerto", “O início do fim”, “O invasor americano”, “O Sal da Terra”, "Ponto final", "Os nomes do amor"," Pink Floyd - The Wall", "A garota dinamarquesa", "Seremos história”, “A história de Rosa Parks"," A partida”, "Era o Hotel Cambridge”, “O vento será sua herança" "Chico Mendes - Cartas da Floresta", "Cinco câmeras quebradas", episódios "San Junipero" e "Nosedive" da série "Black Mirror", "Virunga".

Também foram realizados debates sobre curtas, que abordavam diferentes assuntos, inclusive como o trabalho de legendar alguns filmes que não estavam, ainda, legendados em português, como foi o caso do curta de animação: "Marie Curie - Desenhando minha vida". Adicionalmente iniciou-se também um trabalho de produção de vídeos de divulgação científica que foram disponibilizados na internet, em plataformas de armazenamento de vídeos como o youtube.

Figura 4 - Equipe de bolsistas junto com o coordenador do programa de extensão

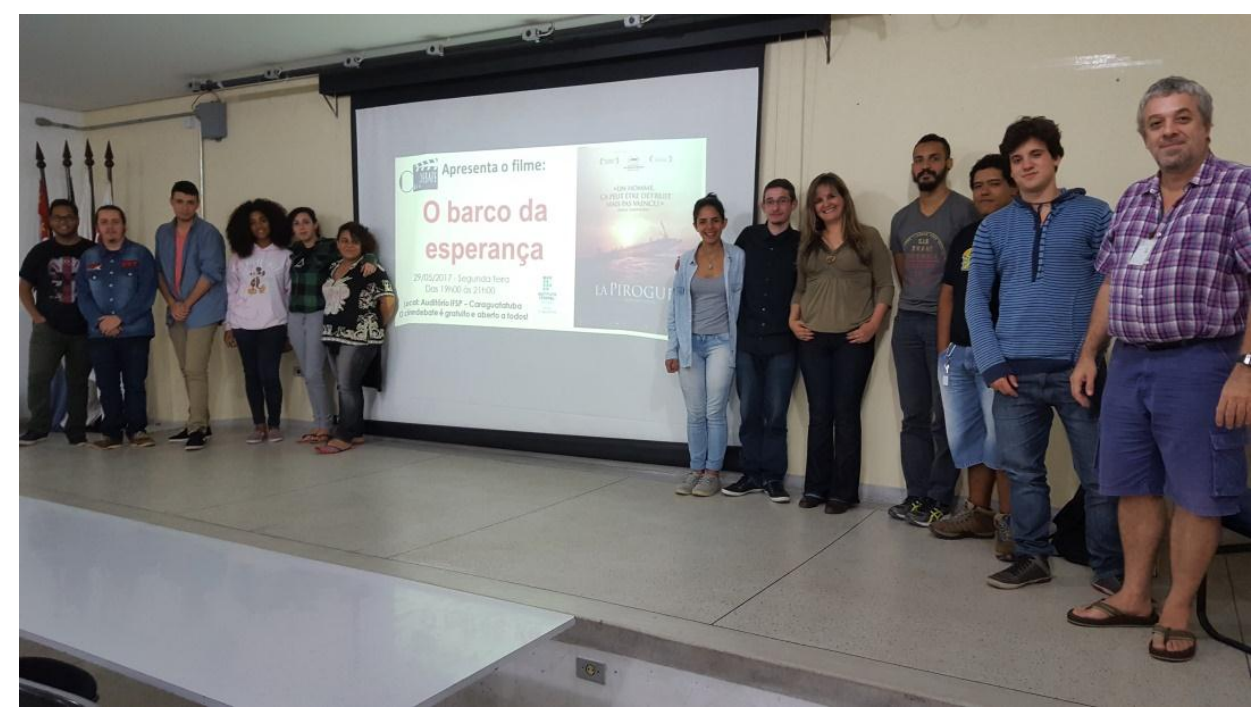

Outro aspecto positivo a ser observado foi à existência de parcerias que foram estabelecidas com outras escolas da região para trazerem seus alunos para participarem de atividades culturais e 
educacionais no IFSP. Foi importante também a realização de parcerias com outros projetos de extensão desenvolvidos no IFSP-Caraguatatuba, como: Projeto "Touba", que envolve a valorização da comunidade de imigrantes senegaleses que residem no litoral norte paulista e o projeto: “Cursinho Popular" que é uma ação do IFSP-Caraguatatuba voltada para preparar alunos e ex-alunos de escolas públicas para as provas do Exame Nacional de Ensino Médio (ENEM), programa este que se iniciou em 2016 e que em 2017 foi desenvolvido no auditório da Escola Estadual Colônia dos Pescadores de Caraguatatuba (SP), por meio de uma colaboração interinstitucional. Em ambos os casos foram estruturadas diversas sessões de cinedebates para atingir os públicos específicos envolvidos nestes projetos.

Figura 5 - Observação do céu noturno realizada após um cinedebate



Os cinedebates são sempre gratuitos e não é necessário se inscrever para assistir os filmes exibidos, basta comparecer no espaço do evento (geralmente o auditório do IFSP-caraguatatuba) no horário da exibição. É uma atividade cultural e educacional de extensão aberta a quaisquer interessados da comunidade interna e externa ao IFSP. Deste modo, muitos dos cidadãos da comunidade local criaram o hábito de ir até o prédio do Instituto Federal para assistir o filme e participar dos debates. É dentro dessas premissas que o projeto pretende "abrir espaço para o novo, para o inusitado, para a possibilidade de experimentar o ainda não 'experienciado' (...)” (FISHER, 2011). 


\section{Discussão}

O projeto de extensão cinedebate vem criando um público que valoriza a cultura, a arte e a diversidade cinematográfica abordada nas sessões. As colaborações com o projeto TOUBA, com o Cursinho Popular e outras instituições de ensino, têm permitido criar uma cultura da valorização da inclusão, da tolerância, do respeito, da solidariedade e do debate aberto de ideias. Tem permitido, também, desenvolver discussões sobre preconceitos disseminados na situação, sobre questões reais que não têm destaque na mídia, sobre situações vivenciadas em outros períodos históricos e sobre temas que são desconhecidos por muitos.

Dentre os diversos assuntos abordados nos cinedebates estiveram: direitos de homossexuais e transexuais, direitos da mulher e machismo, luta por igualdade racial, vida fora da Terra, mudanças climáticas, movimentos sociais, revoluções científicas, momentos históricos importantes (tais como a segunda guerra mundial e o golpe militar de 1964), temas de ficção científica, bullying, biografias de artistas e cientistas, etc. As atividades realizadas procuraram inclusive levar em consideração determinadas datas (dia internacional do meio ambiente, dia da consciência negra, etc.), bem como certos eventos com impactos na sociedade (eclipse, dias específicos de mobilizações sociais, etc.).

As experiências de cinedebates realizados dentro e fora do IFSP-Caraguatatuba, indicaram que a infraestrutura local é fundamental para proporcionar um ambiente propício para a exibição da obra audiovisual e para o debate que ocorre na sequência, tendo um papel crucial para que o evento seja bem-sucedido.

\section{Considerações finais}

O desenvolvimento das diversas atividades de cinedebate possibilitou experiências vivenciais e reflexões sobre como o trabalho com filmes e documentários no contexto educacional, a adequação na escolha da trama da obra e o planejamento minucioso da atividade podem ampliar o repertório cultural e provocar uma discussão importantíssima a respeito de valores e hábitos. Bem como de questões éticas e estéticas, desenvolvendo no cidadão presente uma visão mais ampla a respeito da complexidade do mundo em que vivemos, ajudando a superar reducionismos e preconceitos latentes em nossa sociedade.

Além disso, o debate mediado pela equipe de bolsistas, após a exibição do filme, é um momento propício para promover uma emancipação sobre diversos prismas; a desmistificação de preconceitos, a preocupação com questões ambientais e sociais e a superação de visões de senso 
comum equivocada; para isto é importante trabalhar com imagens cinematográficas que desloquem o espectador dos seus modos de ver a si mesmo e ao "outro" (FISCHER, 2011). De um modo geral, o trabalho com filmes e documentários promove a Cultura, a Arte, a Ciência, a História e a Educação em geral. Os debates realizados após cada exibição são espaços para os presentes explorarem seus pensamentos e suas emoções, mas ao mesmo tempo se aprofundando nos temas abordados por meio das análises críticas estabelecidas. A intermediação da equipe de bolsistas e a colaboração de todos os presentes permitem conhecer melhor diferentes aspectos sobre assuntos polêmicos e encarando problemas de formas não convencionais, o que é crucial para potenciais mudanças de posturas necessárias para um desenvolvimento social e cultural mais harmonioso, de modo a contribuir para a construção de uma sociedade mais democrática.

\section{Referências}

ANDRADE, Adriana de; TEIXEIRA, Ricardo Roberto Plaza. Cinema, educação e tecnologia: contribuições pedagógicas de um projeto de extensão. Revista Interdisciplinar de Tecnologias $e$ Educação: RInTE, Boituva, v. 2, n. 1, jun. 2016. Disponível em: <http://sinte.btv.ifsp.edu.br/index.php/SInTE/article/view/263 >. Acesso em: 11 jun. 2018.

ANDRADE, Adriana de et al. Cine-Debate: História, Ciência e Cultura. Revista Compartilhar, São Paulo, v. 1, n. 1, p.83-86, fev. 2017. Disponível em: <http://ojs.ifsp.edu.br/index.php/compartilhar/issue/viewIssue/56/84>. Acesso em: 11 jun. 2018.

FANTIN, Mônica. Mídia-educação e cinema na escola. Revista Teias, v. 8, n. 14-15, p. 13 pgs., 2007.

FISCHER, Rosa Maria Bueno. Cinema e Pedagogia: uma experiência de formação ético-estética Cinema and Education: anethical-estheticexperience. PerCursos, v. 12, n. 1, p. 139-152, 2011.

MOGADOURO, Claudia de Almeida. Educomunicação e escola: o cinema como mediação possível (desafios, práticas e proposta). 2011. Tese de Doutorado. Universidade de São Paulo.

NAPOLITANO, Marcos. Cinema: experiência cultural e escolar. Caderno de Cinema do Professor, p. 10, 2009.

NAPOLITANO, Marcos. Como usar o cinema nasala de aula. São Paulo: Contexto, 2005. 